\title{
WING ECOMORPHOLOGY OF SEABIRDS FROM JOHNSTON ATOLL ${ }^{1}$
}

\author{
FRITZ HERTEL \\ Department of Biology, University of California, Los Angeles, CA 90095-1606, e-mail: fhertel@ucla.edu \\ LisA T. BALLANCE \\ Ecology Program, NOAA, NMFS, Southwest Fisheries Science Center, 8604 La Jolla Shores Drive, \\ La Jolla, CA 92037
}

\begin{abstract}
Wing morphology of nine species of seabirds from Johnston Atoll in the central tropical Pacific was analyzed to determine how wing size and shape correlated with observed foraging behavior and, in some species, the energetic cost of flight. Red-tailed Tropicbirds (Phaethon rubricauda) and Christmas Shearwaters (Puffinus nativitatis) had lower wing areas, shorter wing spans, and higher relative wing loading than would be predicted from mass alone. Brown Noddies (Anous stolidus) and Red-footed Boobies (Sula sula) had lower wing loading, Brown Boobies (Sula leucogaster) and Sooty Terns (Sterna fuscata) had higher aspect ratios, and Brown Noddies had lower aspect ratio than would be predicted from mass alone. Aspect ratio showed greater intraspecific variation than the other variables. In most cases, predicted differences in wing morphology correlated well with observed foraging differences among species, and species that did not differ significantly in body mass differed with respect to wing size and shape; these morphological differences reflected varying flight and foraging behaviors. Sooty Terns had a higher aspect ratio and higher wing loading than Brown Noddies reflecting their more pelagic lifestyle, and Christmas Shearwaters had a lower aspect ratio and higher wing loading than Wedge-tailed Shearwaters (Puffinus pacificus) reflecting their pursuit plunging behavior.
\end{abstract}

Key words: ecomorphology, flight, Laridae, Phaethontidae, Procellariidae, seabirds, Sulidae, wings.

\section{INTRODUCTION}

Morphological studies usually provide important insights into the relationship between organisms and their ecology, because morphological structures are intimately linked to performance, and performance determines the suite of ecological strategies available to a species. Interspecific variation in morphology is indicative of the different roles played by each species within a community, however the success of characterizing these roles depends on choosing the appropriate morphological features that correspond with the performance character of interest.

Flight is a performance parameter about which much can be learned through the study of ecomorphology. For almost all birds, flight is intimately linked with a suite of morphological traits, all of which are interdependent and relatively highly constrained.

Pelagic seabirds provide an intriguing system in which to study ecomorphological aspects of flight. The spatial scale of pelagic systems is large relative to terrestrial ones (McGowan and

\footnotetext{
${ }^{1}$ Received 2 July 1998. Accepted 22 March 1999.
}

Walker 1993), and some pelagic seabird species traverse hundreds or thousands of kilometers per day on a regular basis in search of food (Strikwerda et al. 1986, Jouventin and Weimerskirch 1990). This is particularly true in the tropics, where productivity is low relative to high latitudes (Ainley and Boekelheide 1993, Ballance and Pitman 1999), and thus there should be strong selection for flight capabilities that allow seabirds to locate and secure prey in the face of diminished feeding opportunities. Some tropical seabirds such as Sooty Terns (Sterna fuscata) and Red-footed Boobies (Sula sula) have metabolic costs of flight much lower than would be predicted based on body mass alone (Flint and Nagy 1984, Ballance 1995), and they exhibit behavioral adaptations that increase flight proficiency, including the use of wind as an energy source (Pennycuick 1982, Ballance 1995, Spear and Ainley 1997). Given these physiological and behavioral adaptations, it is expected that morphological adaptations also exist for proficient flight.

Warham $(1977,1996)$ presented data for several procellariiform species that revealed how wing morphology reflected ecology. For exam- 
TABLE 1. Species sampled from Johnston Atoll. Values represent mean $\pm \mathrm{SE}$. Wing loading in Newtons $\mathrm{m}^{-2}$.

\begin{tabular}{|c|c|c|c|c|c|c|}
\hline Species & $n$ & $\begin{array}{c}\text { Mass } \\
(\mathrm{kg})\end{array}$ & Aspect ratio & $\begin{array}{l}\text { Wing loading } \\
\left(\mathrm{N} \mathrm{m}^{-2}\right)\end{array}$ & $\underset{(\mathrm{m})}{\text { Wing span }}$ & $\underset{\left(\mathrm{m}^{2}\right)}{\text { Wing area }}$ \\
\hline \multicolumn{7}{|l|}{ Procellariiformes } \\
\hline Wedge-tailed Shearwater & 40 & $0.38 \pm 0.01$ & $10.41 \pm 0.06$ & $37.94 \pm 0.63$ & $1.01 \pm 0.01$ & $0.10 \pm 0.001$ \\
\hline Christmas Shearwater & 12 & $0.34 \pm 0.01$ & $10.34 \pm 0.78$ & $51.51 \pm 1.48$ & $0.82 \pm 0.02$ & $0.07 \pm 0.001$ \\
\hline \multicolumn{7}{|l|}{ Pelecaniformes } \\
\hline Brown Booby & 14 & $1.26 \pm 0.06$ & $12.14 \pm 0.13$ & $64.06 \pm 2.38$ & $1.52 \pm 0.06$ & $0.19 \pm 0.004$ \\
\hline Masked Booby & 7 & $1.90 \pm 0.06$ & $12.16 \pm 0.29$ & $84.76 \pm 3.13$ & $1.64 \pm 0.03$ & $0.22 \pm 0.005$ \\
\hline Red-footed Booby & 42 & $1.10 \pm 0.02$ & $11.43 \pm 0.09$ & $54.98 \pm 0.78$ & $1.50 \pm 0.01$ & $0.20 \pm 0.002$ \\
\hline Red-tailed Tropicbird & 15 & $0.65 \pm 0.02$ & $10.92 \pm 0.08$ & $56.67 \pm 1.49$ & $1.11 \pm 0.01$ & $0.11 \pm 0.001$ \\
\hline \multicolumn{7}{|l|}{ Charadriiformes } \\
\hline Sooty Tern & 27 & $0.20 \pm 0.01$ & $11.23 \pm 0.10$ & $26.92 \pm 0.39$ & $0.90 \pm 0.004$ & $0.07 \pm 0.001$ \\
\hline Brown Noddy & 30 & $0.19 \pm 0.003$ & $9.67 \pm 0.06$ & $23.38 \pm 1.89$ & $0.85 \pm 0.004$ & $0.08 \pm 0.001$ \\
\hline White Tern & 2 & $0.11 \pm 0.003$ & $11.12 \pm 0.12$ & $23.54 \pm 0.76$ & $0.70 \pm 0.001$ & $0.04 \pm 0.001$ \\
\hline
\end{tabular}

ple, diving-petrels (Pelecanoididae), which pursue prey underwater using wing propulsion, showed convergent morphological adaptations with auks (Alcidae), which also pursue prey underwater by using their wings. Other studies have suggested that certain wing traits are associated with low energetic cost of flight in seabirds; Southern Giant Petrels (Macronectes giganteus) are similar in mass to some albatrosses but have differently shaped wings and greater flight costs (Pennycuick 1982, Obst and Nagy 1992).

Tropical seabirds must be selected for proficient flight, especially in comparison with high latitude seabirds. They also exhibit a diversity of flight behaviors that reflect ecological differences in searching for and acquiring prey (Ashmole 1971). In this paper we examine the wing morphology of nine seabird species in the tropical Pacific with the premise that wing morphology reflects these ecological differences. Morphological differences are used to make predictions about ecology, which are based on results from previous studies (Norberg 1985, 1989, Rayner 1988, Pennycuick 1989) and are tested by investigating what is known about the distribution and feeding ecology of these seabirds.

\section{METHODS}

\section{STUDY AREA AND SPECIES}

Johnston Atoll, a group of four small islands (each $\leq 2.5 \mathrm{~km}^{2}$ ), is located approximately $1,200 \mathrm{~km}$ southwest of Hawaii in the eastern tropical Pacific $\left(16^{\circ} 45^{\prime} \mathrm{N}, 169^{\circ} 31^{\prime} \mathrm{W}\right)$. Vegetation consists of 3 native and 124 introduced species (Amerson and Shelton 1976). Thirteen species of seabirds currently breed on the atoll and 9 of these, representing three orders and four families of birds, were sampled for this study (Table 1). Birds were live-captured, measured, and released unharmed within a period of $8 \mathrm{~min}$. All species were sampled during the breeding season (incubating, brooding, and/or provisioning young). The feeding behavior of each species was categorized based on their most typical feeding behavior as determined by Ashmole (1971) and from our own field observations.

\section{DATA COLLECTION}

Measurements were collected following the methods outlined by Pennycuick (1989). Body mass $(\mathrm{kg})$, wing length $(\mathrm{m})$, and wing area $\left(\mathrm{m}^{2}\right)$ were recorded for each bird. Wing length was calculated as the rectilinear distance from the sternum, a homologous landmark, to the tip of the outstretched wing along the ventral surface of the bird; wing span was thus twice the wing length (Fig. 1). The fully outstretched wing was traced with the wing positioned ventral side down. This tracing (partial wing area) was later digitized using the program SIGMASCAN (Jandel Corp., San Rafael, California) to determine its area. The tracing was shorter than the wing length because of the body area between the proximal edge of the wing and sternum, known as the root box (Pennycuick 1989). This rectangular area was quantified by multiplying the width of the wing where it meets the body, and the difference between the wing length and the length of the wing tracing (Fig. 1). The root box was added to the partial wing area, thus wing area was twice this value (Fig. 1). 


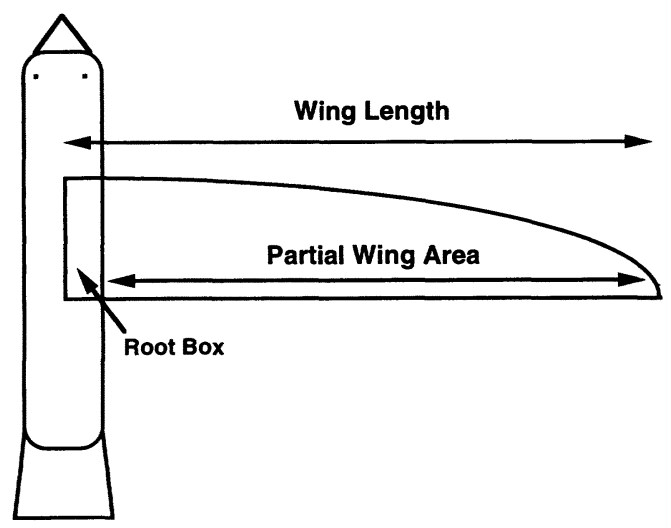

FIGURE 1. Measurements taken of the wing. Wing length measured from the sternum to the tip of the wing, thus wing span $=2 \times$ wing length. Partial wing area calculated from a tracing of the bird wing. Root box quantified by multiplying the width of the wing where it meets the body by the difference between wing length and partial wing length, thus wing area = $2 \times$ (root box + partial wing area).

These data were used to calculate wing loading and aspect ratio, the latter a size-independent variable that can contain significant information (Norberg and Norberg 1988, Rayner 1988). Aspect ratio, a dimensionless number that describes the shape of the wing, was calculated as:

$$
\text { wing } \operatorname{span}^{2} / \text { wing area }
$$

Higher values for this index indicate a comparatively narrower wing, and lower values a comparatively broader wing.

Wing loading describes the weight (force) that is borne per unit area of the wings, or the amount of weight carried by the bird's wings; the units are in Newtons (force) $\mathrm{m}^{-2}$. It was calculated as:

body mass $\times$ gravitational constant (a)/wing area

Larger birds typically have a higher wing loading than smaller birds because of area-volume scaling relationships (Hildebrand 1988). Norberg and Norberg (1988) used relative wing loading (wing loading divided by the cube root of body mass) for comparisons with geometric similarity and to help account for the effects of body size; thus relative wing loading also was used in this analysis. As a group, seabirds typically have long, narrow wings compared with most other birds, and so our comparisons and results are conducted within the context of seabirds.

\section{DATA ANALYSIS}

No sexual distinction within species was made in these analyses either because there was no apparent sexual dimorphism or sample sizes between known sexes were too small for statistical analyses. To determine whether there was a biased effect from species with larger sample sizes, a species mean was generated for all variables and used in all analyses; these results were compared with analyses using individual data. Results were similar in all but one case (see below), therefore only results for individuals are presented.

A Pearson correlation matrix was generated to show relationships among all variables. Body size is an important ecological variable, therefore least-squares regressions of $\log _{10}$-transformed variables (wing area, wing span, aspect ratio, and relative wing loading) were used to investigate allometric relationships between each of these variables and log body mass; the mean absolute value of residuals from the regression indicated which species deviated most for each variable. Species similar in body mass were examined for significant differences in other variables.

Body mass, relative wing loading, and aspect ratio were used to construct a multidimensional morphospace, which provided a graphical representation of the relationships among all species. Axes were represented as standard deviates of the mean value for each variable. All analyses were done using SYSTAT (Wilkinson 1988).

\section{RESULTS}

\section{CORRELATIONS AMONG VARIABLES}

Summary statistics for body mass and wing parameters are given in Table 1. Our results for the two shearwaters agree closely with those of Warham (1977, 1996). Analysis of individual specimens showed a significant correlation among body mass, wing loading, aspect ratio, wing span, and wing area $(r>0.59, P<0.001$ for all variables). The lowest correlations were between aspect ratio and each of the other variables $(0.59<r<0.68)$. Analysis of species means indicated a similar trend with one exception, aspect ratio. Body mass, wing loading, wing span, and wing area were all significantly correlated $(r>0.84, P<0.001$ for all vari- 


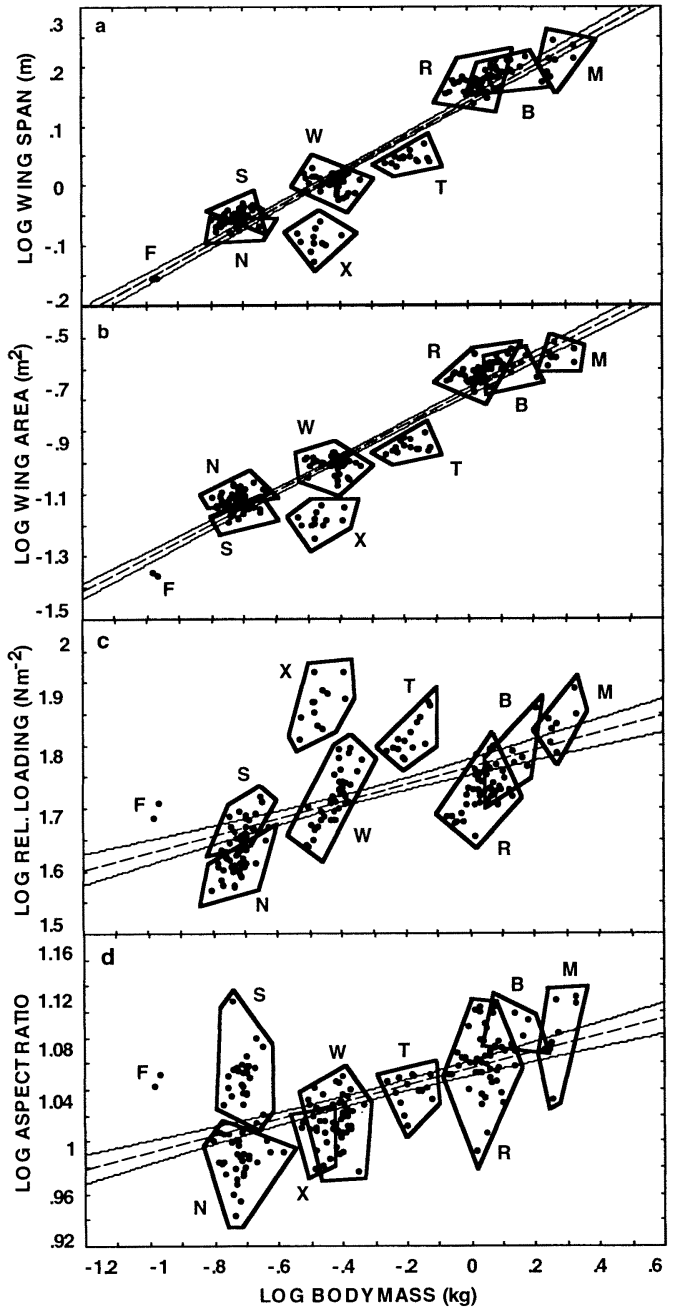

FIGURE 2. Least-squares regressions on log body mass for seabird species from Johnston Atoll for (a) log wing span, (b) log wing area, (c) log relative wing loading, and (d) log aspect ratio. Letter codes: $\mathrm{B}=$ Brown Booby, $\mathrm{F}=$ White Tern, $\mathrm{M}=$ Masked Booby, $\mathrm{N}=$ Brown Noddy, $\mathrm{R}=$ Red-footed Booby, $\mathrm{S}=$ Sooty Tern, $\mathrm{T}=$ Red-tailed Tropicbird, $\mathrm{W}=$ Wedge-tailed Shearwater, $\mathrm{X}=$ Christmas Shearwater.

ables), however there was no significant correlation between aspect ratio and any other variable $(r<0.78, P>0.1)$.

\section{REGRESSIONS WITH LOG BODY MASS}

In general, body mass was a better predictor of wing size than wing shape. There was a significant relationship of body mass with wing span $\left(R^{2}=0.90, P<0.001 ; \mathrm{Y}=0.30 \mathrm{X}+0.14\right.$; Fig. 2a), wing area $\left(R^{2}=0.89, P<0.001 ; \mathrm{Y}=\right.$
$0.53 \mathrm{X}-0.77$; Fig. $2 \mathrm{~b})$, and with relative wing loading $\left(R^{2}=0.35, P<0.001 ; \mathrm{Y}=0.14 \mathrm{X}+\right.$ 1.77; Fig. 2c). The exception was aspect ratio; this relationship was not significant $\left(R^{2}=0.36\right.$, $P=0.06 ; \mathrm{Y}=0.06 \mathrm{X}+1.06$; Fig. $2 \mathrm{~d})$, and intraspecific variation tended to be greater for this variable than the other measures of wing morphology.

Mean regression residuals were generally greatest for two species, which also were farthest from the $95 \%$ confidence intervals, Redtailed Tropicbirds (Phaethon rubricauda) and Christmas Shearwaters (Puffinus nativitatis). Both had shorter wing spans, lower wing areas, and higher relative wing loading than would be predicted from mass alone (Figs. 2a-c, respectively). Brown Noddies (Anous stolidus) and Red-footed Boobies (Sula sula) had greater negative residual values for wing loading, suggesting they have a relatively lower than predicted wing loading (Fig. 2c). Mean residual values of aspect ratios were most positive for Brown Boobies (Sula leucogaster) and Sooty Terns (Sterna fuscata), suggesting higher aspect ratios (narrower wings); mean residual values were most negative for Christmas Shearwaters and Brown Noddies, suggesting lower aspect ratios (wider wings) (Fig. 2d).

\section{SPECIES SIMILAR IN BODY MASS}

ANOVA for all species indicated two species pairs that did not differ significantly in body mass. Sooty Terns and Brown Noddies (hereafter, tern-noddy pair) did not show body mass differences, but were significantly different with respect to all wing parameters $(P<0.001$ for all values). The small sample size $(n=2)$ for White Terns (Gygis alba) precluded their use for statistical comparisons. Wedge-tailed Shearwaters (Puffinus pacificus) and Christmas Shearwaters also did not differ in body mass but showed significant differences for all wing parameters $(P<0.001)$ with the exception of aspect ratio $(P>0.5)$.

\section{GROUP DIVERSITY}

A three-dimensional plot of body mass, aspect ratio, and relative wing loading depicted how species segregated along these axes (Fig. 3). A nested ANOVA showed significant differences at the family and genus level for each variable; boobies and tropicbirds (Pelecaniformes) had greater values for all three variables, terns 


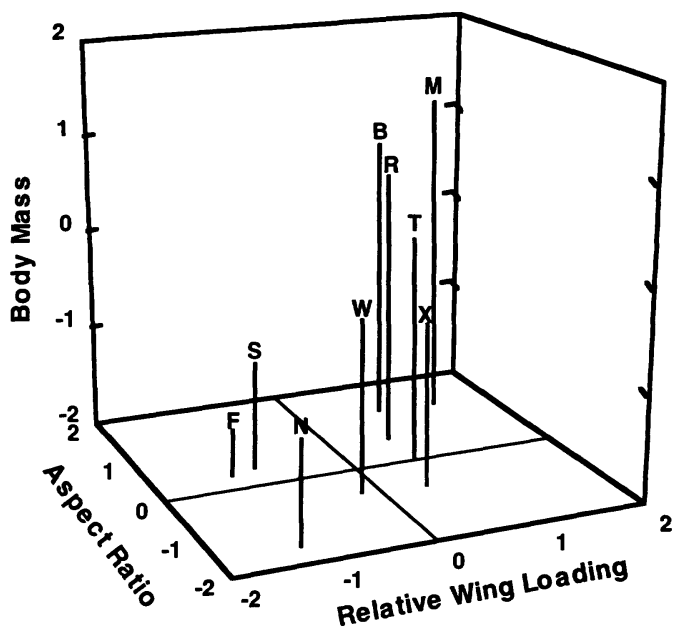

FIGURE 3. Three-dimensional morphospace for body mass, relative wing loading, and aspect ratio for seabird species from Johnston Atoll. Axes plotted as standard deviates of the mean value for each index. Letter codes as in Figure 2. Pelecaniformes (B, M, R, $\mathrm{T}$ ) had greater values for all three variables, Charadriiformes (F, N, S) showed the converse, and Procellariiformes $(\mathrm{W}, \mathrm{X})$ had intermediate values except for aspect ratio, which was similar to Charadriiformes.

(Charadriiformes) showed the converse, and shearwaters (Procellariiformes) had intermediate values except for aspect ratio, which was similar to terns (Table 1, Fig. 3).

\section{DISCUSSION}

\section{BODY SIZE}

Not surprisingly, variables with the highest correlations among each other reflected some measure of size: wing span, wing area, body mass, and to a lesser extent wing loading. Body size is an important determinant of feeding flock composition in the tropical Pacific, particularly in flocks in which boobies were the numerically dominant species (Ballance et al. 1997). Larger body size was important for gaining access to prey while potentially excluding others from the same. In addition, Brown Boobies and Masked Boobies (Sula dactylatra) typically feed by plunge diving, where they enter the water, often from great heights, to seize prey below the surface (Ashmole 1971, Hoyo et al. 1992, Ballance et al. 1997). Masked Boobies are the largest boobies and their size allows them to plunge deeper than Brown Boobies, providing access to prey potentially unavailable to a smaller species.

The comparatively low correlations between aspect ratio and each of the other variables is partly a result of it being a dimensionless number in which the effect of size has been minimized. The coefficient of variation for aspect ratio was greater than for any other variable and in all species. As mentioned previously, size-independent variables are important for illustrating adaptive significance (Norberg and Norberg 1988, Rayner 1988), thus particular attention is given to aspect ratio. With respect to our study, the intraspecific variation in aspect ratio suggests fewer constraints on this variable than other parameters of wing morphology.

\section{MORPHOLOGICAL PREDICTIONS OF ECOLOGY}

Results from empirical and theoretical research designed to determine general relationships between wing morphology and flight performance can be used in this particular study to predict ecology from morphology. For example, aspect ratio might be used as a predictor of distance traveled when foraging; the more far-ranging the species, the higher the aspect ratio (Norberg 1985, Rayner 1988). This relationship is exemplified by albatrosses, among the most far-ranging of seabirds (Jouventin and Weimerskirch 1990) and those with the highest aspect ratios (Hildebrand 1988, Warham 1996).

Similarly, wing loading might be used as a predictor of distance traveled when foraging because the energetic cost of flight is likely to be positively correlated with wing loading. For example, Obst and Nagy (1992) found that Southern Giant Petrels (Macronectes giganteus) had greater flight costs, higher wing loading, and lower aspect ratio than several albatrosses of similar mass; the former regularly feed on shore or in nearshore waters, whereas the latter rarely do so (Harrison 1983, Hoyo et al. 1992).

A third prediction is that wing loading will be negatively correlated with glide/flight speed (Pennycuick 1989). Thus, we would predict that only those species with relatively low wing loading will be able to utilize foraging strategies that require low flight speeds. This would be especially important in tropical regions where wind speeds are typically lower compared with winds at higher latitudes.

Tern-noddy pair. The tern-noddy pair did not differ significantly in body mass, yet they differed significantly in all wing parameters measured. Sooty Terns had a higher aspect ratio, 
greater wing loading, and longer wing span (Table 1). Therefore, we expect them to have lower flight costs, range farther to forage, and fly at greater speeds than Brown Noddies.

These predictions are largely supported by distributional patterns. Sooty Terns forage over great distances $(80-500 \mathrm{~km})$ and remain at sea for months to years, rarely resting on the water (Pitman 1986, Flint 1991). In the eastern tropical Pacific, they are found in greatest abundance in areas of low productivity (Ballance et al. 1997). Thus we expect that selection for proficient locomotion would be strong in this species, and indeed Sooty Terns have flight costs much lower than would be predicted from mass alone (Flint and Nagy 1984). These differences were believed to be due largely to wing morphology, in a manner consistent with the results presented here. In contrast, Brown Noddies forage closer to shore and usually return to land to roost at night (Ashmole 1968). To our knowledge, flight costs for this species have not been quantified, but it would seem that selection for low flight cost, and associated wing morphology, would not be as strong as for the more widely foraging Sooty Tern.

Shearwaters. The two shearwaters also did not differ significantly in body mass, but they differed significantly in most wing measurements. Wedge-tailed Shearwaters had greater wing span, greater wing area, and lower wing loading than Christmas Shearwaters, but were similar in aspect ratio; the latter species fell notably below the regression for wing span and wing area, and above that for wing loading (Figs. 2a-c, respectively). Accordingly, one might predict that Wedge-tailed Shearwaters would have slower flight speeds, and increased maneuverability at such speeds, both resulting from low wing loadings (Norberg 1985, Rayner 1988). Additionally, because the power required for flight can be reduced by combining low wing loading with high aspect ratio (Rayner 1988), we expect flight costs would be lower for Wedgetailed than for Christmas Shearwaters.

These predictions are difficult to test, given our lack of knowledge about the at-sea ecology of shearwaters, particularly Christmas Shearwaters. Both species forage far from shore (Harrison 1983, Pitman 1986) and both commonly feed in flocks in association with subsurface predators (Ballance et al. 1997). We suspect that the morphological differences between them re- flect differences in feeding behavior. For example, Wedge-tailed Shearwaters are known to pursue prey aerially (Ballance 1993), whereas Christmas Shearwaters have not been recorded to do so. Christmas Shearwaters also pursuit dive (underwater flight) more frequently than do Wedge-tailed Shearwaters (Ashmole 1971), so a higher wing loading (smaller wing area) might reflect this behavior given the greater force required to move the wings through water relative to air. In support of this idea, a relatively high wing loading was reported for diving-petrels and alcids, both of which use wing propulsion underwater to pursue their prey (Warham 1977, 1996). More information is needed on the energetics and feeding behavior of these shearwaters.

Boobies. The three booby species differed significantly in body mass, however Red-footed and Brown Boobies differed only slightly. Redfooted Boobies had a significantly lower aspect ratio and wing loading than the other two species, wing loading being anomalously low (Fig. 2c). We would therefore predict that Red-footed Boobies would have a lower cost of flight and would not forage as widely as Brown Boobies.

These predictions appear to be only partly supported. Red-footed Boobies forage over much greater distances than Brown Boobies, the latter foraging in more nearshore waters (Pitman 1986, Hoyo et al. 1992). For Red-footed Boobies, Ballance (1995) found their measured cost of flight well below that predicted by aerodynamic theory for a bird of their size. Differences in aspect ratio may be explained, in part, through differences in feeding behavior. Whereas most boobies use plunge-diving (Ashmole 1971, Hoyo et al. 1992, Ballance et al. 1997), Redfooted Boobies in the tropical Pacific also feed by pursuing and capturing flying fish in the air (Ballance 1993). This behavior requires quick maneuvering, and presumably, a low cost of flight. Relatively short, narrow wings would be advantageous for quick maneuvering (Rayner 1988) but precisely how this relates to aspect ratio requires further investigation. Red-footed Booby wings may represent a compromise between selection for a low cost of flight/wide foraging range (higher aspect ratio), and an aerial pursuit predatory behavior (lower aspect ratio). More behavioral data in other regions and more sulid species are needed to resolve this relationship. 
Tropicbirds. Red-tailed Tropicbirds had shorter wing span, lower wing area, and greater wing loading (Figs. 2a-c, respectively) than predicted based on body mass; aspect ratio was slightly lower than expected (Fig. 2d). This morphology predicts that flight speed and cost of flight would be high (Norberg 1985, Rayner 1988).

Red-tailed Tropicbirds travel great distances (200-500 km) when foraging (Pitman 1986, Schreiber and Schreiber 1993), but not much is known regarding their foraging ecology other than that they are typically plunge divers (Ashmole 1971, Hoyo et al. 1992, Schreiber and Schreiber 1993). It seems paradoxical that a pelagic feeder would have morphological features resulting in high cost of flight, although feeding areas that are predictable in space and time might explain this wing morphology and consequent performance traits. Red-tailed Tropicbirds rarely feed in flocks in association with subsurface predators (Schreiber and Schreiber 1993, Ballance et al. 1997), despite the fact that this is a prevalent foraging strategy for many tropical seabird species (Au and Perryman 1985, $\mathrm{Au}$ and Pitman 1986). Flock feeding requires the ability to hover in order to gain access to the rapidly moving areas at the water surface where prey is available, and maneuverability in order to avoid collisions with the numerous other birds feeding in close proximity. Low wing area, short wing span, and high wing loading are not features that permit the slow flight necessary for such maneuverability. Further investigation of tropicbird feeding behavior and energetic consequences is needed.

\section{GROUP DIVERSITY}

Before making valid functional comparisons or interpretations across taxa, differences in phylogeny should be accounted for, and methods have been developed to help account for these differences (Felsenstein 1985, Gittleman and Kot 1990, Hertel and Lehman 1998). Results from the three-dimensional group analysis (Fig. 3) suggest there is a phylogenetic component that needs to be addressed; this will be done in the future by the inclusion of more species and by comparing seabirds from Johnston Atoll with other pelagic groups in the eastern tropical $\mathrm{Pa}$ cific.

\section{FUTURE CONSIDERATIONS}

Organisms sometimes are assumed to be optimally adapted to their environment. However, any particular trait is likely to be suboptimal when viewed in only one context; animals probably exhibit some combination of morphological traits that potentially reflect a compromise for multiple functions. An example is the Red-footed Booby; this species is highly pelagic, a niche that would select for high aspect ratio, yet its foraging mode of aerial pursuit of flying fish might select for a comparatively lower aspect ratio for maneuverability.

Limitations on community structure and the diversity of functional types will likely change with different species. For seabirds, breeding assemblages also are determined by other factors such as available substrates, island size, and stochastic events. Many seabird colonies also have been affected by human factors within the past few hundred years (Steadman 1995) and so these historical disturbances on seabird distribution must also be considered whenever possible. Whether character or competitive displacement occurs among seabirds based on wing ecomorphology will require more species in each functional and ecological category described above, and a comparison among established pelagic communities.

\section{ACKNOWLEDGMENTS}

We thank D. Jacobs, W. Koenig, R. Pitman, T. Plummer, J. Warham, and an anonymous reviewer for helpful comments. Funding for LTB was received from the American Ornithologists' Union, the Department of Biology at UCLA, the Hawaii/Pacific Islands National Wildlife Refuge Complex of the U.S. Fish and Wildlife Service, and the Southwest Fisheries Science Center of the National Oceanic and Atmospheric Administration.

\section{LITERATURE CITED}

AINley, D. G., AND R. J. BoEKelheIDE. 1993. An ecological comparison of oceanic seabird communities of the south Pacific Ocean. Stud. Avian Biol. 8:2-23.

Amerson, A. B., JR., AND P. C. Shelton. 1976. The natural history of Johnston Atoll, central Pacific Ocean. Atoll Res. Bull. No. 192. Smithson. Inst., Washington, DC.

Ashmole, N. P. 1968. Body size, prey size, and ecological segregation in five sympatric tropical terns (Aves: Laridae). Syst. Zool. 17:292-304.

Ashmole, N. P. 1971. Sea bird ecology and the marine environment, p. 223-286. In D. S. Farner and J. R. King [eds.], Avian biology. Vol. 1. Academic Press, New York.

Au, D. W. K., AND W. L. Perryman. 1985. Dolphin habitats in the eastern tropical Pacific. Fishery Bull. 83:623-643.

Au, D. W. K., AND R. L. Pitman. 1986. Seabird inter- 
actions with dolphins and tuna in the eastern tropical Pacific. Condor 88:304-317.

Ballance, L. T. 1993. Community ecology and flight energetics in tropical seabirds of the eastern $\mathrm{Pa}$ cific: energetic correlates of guild structure. Ph.D. diss., Univ. California, Los Angeles, CA.

BALlANCE, L. T. 1995. Flight energetics of free-ranging Red-footed Boobies (Sula sula). Physiol. Zool. 68: 887-914.

Ballance, L. T., and R. L. Pitman. 1999. Feeding ecology of tropical seabirds. Proc. Int. Ornithol. Congr. 22, in press.

Ballance, L. T., R. L. Pitman, and S. B. Reilly. 1997. Seabird community structure along a productivity gradient: importance of competition and energetic constraint. Ecology 78:1502-1518.

FELSENSTEIN, J. 1985. Phylogenies and the comparative method. Am. Nat. 125:1-15.

FLINT, E. N. 1991. Time and energy limits to the foraging radius of Sooty Terns Sterna fuscata. Ibis 133:43-46.

Flint, E. N., AND K. A. NAGY. 1984. Flight energetics of free-living Sooty Terns. Auk 101:288-294.

Gittleman, J. L., AND M. KoT. 1990. Adaptation: statistics and a null model for estimating phylogenetic effects. Syst. Zool. 39:227-243.

HARRISON, P. 1983. Seabirds: an identification guide. Houghton Mifflin, Boston.

HeRTEL, F., AND N. LEHMAN. 1998. A randomized nearest-neighbor approach for assessment of character displacement: the vulture guild as a model. J. theor. Biol. 190:51-61.

HILDEBRAND, M. 1988. Analysis of vertebrate structure. 3rd ed. John Wiley and Sons, New York.

Hoyo, J., A. Elliott, and J. Sargatal. 1992. Handbook of the birds of the world. Vol. 1. Lynx Editions, Barcelona.

Hoyo, J., A. Elliott, and J. Sargatal. 1996. Handbook of the birds of the world. Vol. 3. Lynx Editions, Barcelona.

Jouventin, P., AND H. WeIMERSKIRCH. 1990. Satellite tracking of Wandering Albatrosses. Nature 343: 746-748.

McGowan, J. A., AND P. W. Walker. 1993. Pelagic diversity patterns, p. 203-214. In R. E. Ricklefs and D. Schluter [eds.], Species diversity in ecological communities. Univ. Chicago Press, Chicago.

NORBERG, U. M. 1985. Gliding, flying, and soaring, p.
129-158. In M. Hildebrand, D. M. Bramble, K. F. Liem, and D. B. Wake [eds.], Functional vertebrate morphology. Harvard Univ. Press, Cambridge, MA.

NORBERG, U. M. 1989. Vertebrate flight. Springer-Verlag, New York.

NorbERG, U. M., AND R. A. NoRBERG. 1988. Ecomorphology of flight and tree-trunk climbing in birds. Proc. Int. Ornithol. Congr. 19:2271-2282.

OBST, B. S., AND K. A. NAGY. 1992. Field energy expenditures of the Southern Giant-Petrel. Condor 94:801-810.

PenNyCuICK, C. J. 1982. The flight of petrels and albatrosses (Procellariiformes) observed in South Georgia and its vicinity. Phil. Trans. Roy. Soc. Lond. B 300:75-106.

PenNyCuICK, C. J. 1989. Bird flight performance. Oxford Univ. Press, Oxford.

PITMAN, R. L. 1986. Atlas of seabird distribution and relative abundance in the eastern tropical Pacific. Southwest Fisheries Center, Administrative Rep. No. LJ-86-02C. Southwest Fisheries Center, La Jolla, CA.

RAYNER, J. V. 1988. Form and function in avian flight. Current Ornithol. 5:1-66.

SCHREIBER, E. A., AND R. W. SCHREIBER. 1993. Redtailed Tropicbird (Phaethon rubricauda. In A. Poole and F. Gill [eds.], The birds of North America, No. 43. The Academy of Natural Sciences, Philadelphia, and the American Ornithologists' Union, Washington, DC.

SpeAR, L. B., AND D. G. AINLEY. 1997. Flight behaviour of seabirds in relation to wind direction and wing morphology. Ibis 139:221-233.

Steadman, D. W. 1995. Prehistoric extinctions of Pacific island birds: biodiversity meets zooarcheology. Science 267:1123-1131.

Strikwerda, T. E., M. R. Fuller, W. S. SEegar, P. W. HOWEY, AND H. D. BLACK. 1986. Bird-borne satellite transmitter and location program. Johns Hopkins APL Tech. Digest 7:203-208.

WARHAM, J. 1977. Wing loadings, wing shapes, and flight capabilities of Procellariiformes. New Zealand J. Zool. 4:73-83.

WARHAM, J. 1996. The behavior, population biology and physiology of the petrels. Academic Press, New York.

WILKINSON, L. 1988. SYSTAT: the system for statistics. SYSTAT, Inc., Evanston, IL. 